\title{
Short-term impact of PM2.5, PM10, and PMc on mortality and morbidity in the agglomeration of Warsaw, Poland
}

\author{
Katarzyna Maciejewska ${ }^{1}$ (D)
}

Received: 1 April 2019 / Accepted: 28 April 2020 / Published online: 13 May 2020

(C) The Author(s) 2020

\begin{abstract}
The work presents the results of short-term health effects assessment of particulate matter (PM) in Warsaw, the capital of Poland. The influence of three PM fractions, PM10 (particles of aerodynamic diameter $<10 \mu \mathrm{m}$ ), PM2.5 (particles of aerodynamic diameter $<2.5 \mu \mathrm{m}$ ), and PMc (coarse fraction of diameter between 2.5 and $10 \mu \mathrm{m}$ ), modeled by the CALMET/CALPUFF system, has been studied in the period of 2013-2014. Six population health endpoints; daily counts of all-cause (ALL), cardiovascular (CV), and respiratory (RS) death cases; and ALL, CV, and RS hospital admissions were investigated with the use of statistical time series analysis via nonparametric generalized additive model (GAM) approach. The results show that PM2.5 increases the relative risk (RR) of ALL premature deaths by $0.7 \%$ per $10 \mu \mathrm{g} / \mathrm{m}^{3}$, as well as of CV mortality by $0.9 \%$. PM10 exposures reveal the largest influence on mortality in a 2-day lag: $0.3 \%$ for all causes and $0.4 \%$ for CV causes, while for RS causes only in the elderly group (above 65 years, $1.4 \%$ ) and for males $(2.1 \%)$. The risk of hospitalizations increases with elevated PMc levels by $2.5 \%, 2.1 \%$, and $4.6 \%$ for ALL, CV, and RS hospital admissions, respectively. The results suggest that the research on PM impact on health should concentrate more on attempts to assign specific health outcomes to PM originating from different types of sources, characterized by different granulation, as well as physical and chemical properties of emitted particles.
\end{abstract}

Keywords Particulate matter $\cdot$ Mortality $\cdot$ Hospital admissions $\cdot$ CALPUFF $\cdot$ Time series study $\cdot$ Short-term health impact

\section{Introduction}

Insufficient air quality in cities is one of the biggest challenges of present air quality management in the European Union (EU). According to the World Health Organization (WHO 2014), in 2012, the number of premature deaths due to outdoor air pollution worldwide reached 3.7 million. The 2013 Global Burden of Disease study has shown that poor indoor air quality and ambient air pollution are the 7th and the 12th leading global health risk factors, respectively (Forouzanfar et al. 2015). In the EU, the number of premature deaths in 2014 attributed to $\mathrm{PM} 2.5, \mathrm{NO}_{2}$, and $\mathrm{O}_{3}$ was estimated as $399,000,75,000$, and 13,600, respectively (EEA 2017).

PM seems to be of a major concern especially in the region of Central-Eastern Europe, Northern Italy, and the Balkans; however, also the cities in Western Europe experience episodes of concentrations exceeding the existing air quality standards (EEA 2017). Depending on the location, various factors

Katarzyna Maciejewska

katarzyna.maciejewska@pw.edu.pl

1 Warsaw University of Technology, Warsaw, Poland are the leading causes of such situation. Intensity of traffic, structure of fuel mix used in power generation, industry and residential sectors, level of industrialization, heat supply network development, and geographic and climatic aspects play a key role in determining air quality in urban areas (JudaRezler and Toczko 2016). In Western Europe, road transport is considered the most important source of local air pollution in cities (Belis et al. 2013), while most of the urban areas in Poland, and especially in the southern part of the country, are strongly affected by individual heating activities (Juda-Rezler et al. 2011; Sówka et al. 2012; Reizer and Juda-Rezler 2016). However, Warsaw diverges from this pattern: big coverage of the central heat supply network, combined with very intensive traffic, makes the city more alike other European capitals rather than a typical Polish agglomeration (Maciejewska et al. 2015; Juda-Rezler et al. 2020). Therefore, the first analysis of health effects of air quality in Warsaw is an interesting national case study, especially in the face of quite small number of studies in this field performed so far in Poland (Tainio et al. 2014; Tainio 2015; Holnicki et al. 2017a; Holnicki et al. 2018).

Elevated concentrations of PM are recognized as a peculiar hazard especially since the Great London Smog in 1952, with 
a toll of about 12 thousand fatalities (Bell and Davis 2001). Since then, a vast amount of research has been done to quantitatively determine the risks associated with the exposure to PM10 and PM2.5 (see, e.g., Cassee et al. (2013), Kim et al. (2015), Royal College of Physicians (2016)). PM is now recognized as carcinogenic to humans (IARC 2013) and is also considered as one of the leading factors of $\mathrm{CV}$ diseases such as stroke, ischemic heart disease, or myocardial infraction, as well as RS conditions, including chronic obstructive pulmonary disease (COPD), asthma, and bronchitis; estimated reduction of life expectancy in Europe due to PM exposure is almost 9 months (WHO 2013).

Health effects assessment studies include a broad range of approaches and methodologies: epidemiological, cohort, toxicological, in vitro, animal model studies, etc. Up to date, the epidemiological approach is likely the most common one. Specifically, studies based on statistical data related to population's health condition (including mainly the observations on mortality and morbidity) are performed frequently, due to easy access to such databases. Such studies are carried out within both long- and short-term perspectives. Long-term approach is applied to determine the effects of continuous exposure (within a period of at least several years), while shortterm studies aim at recognizing the acute health effects and risks, especially related to the so-called episodes of air pollution (Rückerl et al. 2011; WHO 2013). Up to date, the only short-term air pollution health effects assessment study in Poland was performed within the APHEA (air pollution and health, the European approach) project, which included four Polish cities: Łódź, Cracow, Poznań, and Wrocław (Wojtyniak and Piekarski 1996; Rabczenko et al. 2005). In terms of Warsaw, Tainio et al. (2014) have analyzed the citywide variability of the intake fractions of seven pollutants including PM2.5 and PM10, while Badyda et al. (2016) have compared the spirometric performance of the inhabitants of Warsaw with the results obtained by a control group living in a clean rural area.

The aim of this work was therefore to fill an existing gap of knowledge on the short-term influence of PM on the health of the inhabitants of Warsaw, one of the biggest agglomerations in the region of Central-Eastern Europe, and to compare the results with similar ones from other cities worldwide in order to estimate the all-cause, $\mathrm{CV}$, and RS relative risks related to acute exposure to various size fractions of PM.

\section{Material and methods}

The analysis was done for a 2-year period of 2013-2014, for the capital of Poland, Warsaw. Located in the Masovian Province in central Poland, Warsaw, is a 1.74 million city with an area of 51.7 ha and an average density of 3372 inhabitants per $\mathrm{km}^{2}$ (CSO 2016). The city is highly urbanized, with a dense network of roads and railways, but rather low level of industrialization, except from a few large emission point sources, dominated by two combined heat and power plants: Siekierki and Żerań.

For the purposes of the study, a modeling system was assembled. The main aims of this system were (a) to estimate average daily exposure of the inhabitants to three fractions of PM (PM2.5, PM10, PMc) and (b) to asses a potential risk of population mortality and morbidity related to these pollutants in the short-term perspective. The core of this system consists of two models: CALMET/CALPUFF air quality dispersion model and a generalized additive model (GAM) which is a statistical tool for time series analysis.

CALPUFF is an advanced Gaussian puff model developed by exponent (Barclay and Scire 2011), and its 5.8.4 version (applied in this study) is currently recommended by the US Environmental Protection Agency (USEPA) for simulations on regional $(<200 \mathrm{~km})$ and urban scales (Holmes and Morawska 2006; Holnicki et al. 2017b). It is a multi-layered, non-steady-state Lagrangian model, basing on the assumption that an emitted load of pollutants can be divided into small puffs, released to the atmosphere in the $\Delta \mathrm{t}$ time intervals, which then travel along trajectories calculated separately for each puff. The dispersion module of the model is driven by wind fields generated by CALMET preprocessor, which also calculates various parameters related to atmospheric stability (determined by the Monin-Obukhov length) and to the kinetics of the mixing layer. Input data for CALMET was provided in $5 \mathrm{~km}$ resolution from the Weather Research and Forecasting Model (WRF, National Center for Atmospheric Research), along with the physiographic characteristics of the area and the land use data from CORINE Land Cover 2009 (CLC2009, European Environment Agency). Emission inventory was organized into the categories of point, linear and area sources, and provided both for the territory of Warsaw and for a $30 \mathrm{~km}$ wide band surrounding the city. Boundary conditions were introduced in 1-h time resolution from the Comprehensive Air Quality Model with extensions (CAMx, ENVIRON, 2004) run in the domain covering the whole Poland. All input data, as well as WRF and CAMx modeling results, were shared, thanks to the courtesy of the Voivodship Inspectorate of Environmental Protection in Warsaw. CALPUFF modeling grid resolution was set to $500 \mathrm{~m}$ over Warsaw (total of 2248 receptor points) and $2.5 \mathrm{~km}$ over the outskirts of the city. The modeled 1-h concentrations of three PM fractions (PM2.5, PM10, and PMc-coarse fraction of grain sizes between 2.5 and $10 \mu \mathrm{m}$ ) were filtered to detect and remove highly overestimated values, which are occasionally generated by the model, especially in the case of very weak wind velocities (Holnicki et al. 2016), and then, 24-h average concentrations for each receptor point were calculated. The results for PM2.5 and PM10 were subsequently evaluated against the measurement results available from the air quality monitoring stations 
located within the main domain. For model evaluation, the Delta methodology, elaborated by the Forum for Air Quality Modeling in Europe, Joint Research Centre (FAIRMODE JRC), was applied. The main feature of this approach is the claim that not only model results but also ground-based measurements bear uncertainties, and therefore not the values themselves, but rather the confidence intervals of both modeled and measured data should be compared and assessed. For details of the method, see Thunis et al. (2012) and Thunis and Cuvelier (2016). Finally, in order to estimate the exposure of a typical inhabitant of Warsaw, spatial average concentration from all receptor points in the city, weighted by the population density grid, was calculated on a daily basis:

$E_{i}=\sum_{j=1}^{2248} C_{j} \cdot \frac{m_{j}}{M}$

where $E_{i}$ is the exposure of a typical inhabitant of Warsaw on day $i$; $c_{j}$ is concentration of pollutant in $\mathrm{j}$-th grid cell (2248 is the number of grid cells in modeling domain); $m_{j}$ is population in $\mathrm{j}$-th grid cell; and $M$ is the total population of Warsaw. The population density grid for Warsaw was elaborated based on the spatial population data provided by the Main Office of Geodesy and Cartography of Poland.

Populational short-term health effects related to the exposure to air pollutants can be estimated within a number of different approaches. For the purpose of this study, statistical nonparametric generalized additive Poisson regression models (GAM) for Warsaw were built according to the protocol elaborated under the APHEA-2 project (air pollution and health, the European approach phase 2) (Katsouyanni et al. 2001; Rabczenko et al. 2005). For methodological details, see, e.g., Rabczenko and Wojtyniak (2005) and Katsouyanni and Samet (2009).

GAM allows to include and control the nonlinear dependence of daily mortality and hospital admissions on time (season) and weather. Conceptual formulation of the model is given by:

$\ln \left[E\left(Y_{t}\right)\right]=\alpha_{0}+\sum s_{i}\left(X_{i t}\right)+\sum \beta_{i} I_{i t}+\gamma \cdot P_{t}$

where $E\left(Y_{t}\right)$ is the expected value of the daily count of the relevant health outcome, $X_{i t}$ is the value of predictor variable $i$ on day $t, s_{i}$ are the smooth functions (splines) of these variables, $\beta_{i}$ are the effect estimates for indicator variables $I_{i t}$, and $\gamma$ is the effect estimate for the pollutant $P_{t}$. The spline functions of $X_{i}$ factors represent long- and short-term changes of mortality/morbidity, as well as the influence of meteorological conditions on the investigated health endpoints.

The most important input data for GAM is the time series of daily prevalence of an analyzed health endpoint in the population of interest. In this study, six health endpoints were considered: daily numbers of ALL (ICD-10 codes from A00 to R99), CV (I00-I99) and RS (J00-J99) deaths and hospital admissions (only the urgent cases, excluding the scheduled ones), and the respective datasets were shared thanks to the courtesy of the National Institute of Public Health-National Institute of Hygiene. As described in Dominici et al. (2002) and Rabczenko and Wojtyniak (2005), GAM analysis is a stepwise procedure. First, the nonparametric part of the model is constructed: penalized splines are fitted to reflect the changes of counts of the investigated health effect in long- and shortterm time cycles (the indicators of the year and of the day of the week were included as factors in GAM), as well as to control for the influence of meteorological conditions (temperature, air pressure, wind velocity, relative humidity, and precipitation) on the daily mortality/hospital admissions number. The number of degrees of freedom used for this fitting was chosen based on the analysis of the partial autocorrelation function (PACF). For each of the six analyzed health endpoints, a separate "base" GAM model was constructed this way. Afterward, each base GAM model was complemented by including (as a linear term) the time series of PM concentrations-one size fraction at a time. To account for the possible time shift of the effect relative to air pollution levels, the lags of 1 and 2 days were also considered, i.e., the possibility that an acute health effect may occur 1 or 2 days after exposure was taken into account. As a result of GAM models, population's relative risks (RR) were obtained for each particular health endpoint and for each of the PM fractions. By definition, RR is described as:

$R R=\frac{\text { prevalence in the exposed group }}{\text { prevalence in the non-exposed group }}$

However, in the case of air pollution, and especially in an urban environment, there are no people that are not exposed at all. Therefore, RR was calculated in relation to a $10 \mu \mathrm{g} / \mathrm{m}^{3}$ increase of concentrations. $\mathrm{RR}$ indicator should be understood as follows: $\mathrm{RR}<1$ indicates reverse influence of the pollutant on health endpoint; $R R=1$ indicates no effect; and $R R>1$ indicates positive relation-an increase of concentrations increases the risk of health outcomes in the population. A result is considered statistically significant, if the confidence interval (CI) of estimated RR does not include 1; $p$ value for this study was set at 0.1 . In further text, the values of risk increase (expressed in \%) will be presented, e.g., for $\mathrm{RR}=1.012$; the risk increase equals $1.2 \%$.

\section{Results and discussion}

Before analysis, CALPUFF modeling results were calibrated to better fit the values measured at the same time at the monitoring stations in Warsaw. Fitting was conducted according to own methodology, described in Maciejewska (2017). 
Average, minimum, and maximum exposures to PM2.5, PM10, and PMc in Warsaw, after calibration and weighting by the population density grid, are presented in Table 1. Such approach allows for estimation of the exposure of the whole population, bearing in mind that no data on addresses of the deceased/hospitalized people was available. The time series of PM2.5, PM10, and PMc concentrations in 2013-2014 are presented in Fig. 1.

Mean exposures to PM2.5, PM10, and PMc fractions during the study period (2013-2014) were estimated at $25.7 \mu \mathrm{g} /$ $\mathrm{m}^{3}, 50.7 \mu \mathrm{g} / \mathrm{m}^{3}$, and $24.9 \mu \mathrm{g} / \mathrm{m}^{3}$, respectively.

The highest average concentrations occur in winter; however, maximum levels were obtained in the fall season (26.11.2014). A combination of low temperatures, intensive heating activities, and atmospheric conditions unfavorable for dispersion was likely the cause of such event. Inter-seasonal variability of PMc concentrations is the lowest among the three fractions, most likely because of fairly constant sources of PMc, which mainly consists of crustal and resuspension dust. On the contrary, PM2.5 originates from both traffic (relatively constant throughout the year) and heating activities, with the latter very much dependent on the season of the year. That is why winter average concentrations of this fraction are over threefold higher than the summer ones. In Fig. 1, clear seasonal pattern, characterized by strong contrasts between cold and warm periods, is clearly visible. The city of Warsaw is surrounded by numerous smaller towns and suburbs, which are the most important source areas for PM emitted from residential sector (Holnicki et al. 2018; Juda-Rezler et al. 2020). In Warsaw, around $80 \%$ of the total living space is centrally heated by the municipal heating network; therefore, individual heating is also present in the city itself, mainly in the districts of Ursus, Targówek, Praga, and Wawer (western, north-eastern, and south-eastern parts of the city). According to the model results, PM2.5 constitutes $50.7 \%$ of PM10 mass across Warsaw; therefore, the seasonal variability of PM2.5 is also reflected in the PM10 profile (see Fig. 1), but relative differences are smaller in this case: winter concentrations reach twice the value of the average summer levels. PM2.5 to PM10 ratio varies across seasons, with the lowest mean level in summer (0.38) and the highest in winter (0.59). On a daily basis, this range spans from 0.25 up to 0.73 in the whole study period. In general, when compared with ratios calculated based on measurement data from monitoring stations, the ratios of modeled PM2.5 to PM10 seem to be underestimated. Average measured PM2.5/PM10 ratio in the 2013-2014 period reached 0.67 ; however, the daily ratios were much more variable, ranging from 0.09 to 0.99 (excluding the days in which PM2.5 concentration exceeded the PM10 level measured at the same station-such cases constituted around 7\% of the study period). The difference between modeled and measured ratios is due to the general tendency to underestimate PM2.5 levels by the model (see Table 3). Moreover, the modeled ratios regard PM concentrations averaged over the whole modeling domain, while the measurements are available for a few selected points only.

In general, the inhabitants of Warsaw are exposed to moderate PM concentrations; however, episodes of high concentrations also occur in the city, especially during the heating season, which in Poland lasts from the beginning of October until the end of March, based on the calculation of the heating degree days (Juda-Rezler et al. 2020).

The evaluation of CALPUFF model results was carried out against the measurement results from 4 stations for PM2.5 and 6 stations for PM10. The nearest receptor point from the modeling grid was assigned to each of the sites. Short characteristics of the stations are given in Table 2 .

According to the Delta methodology described in e.g. Thunis et al. (2012) and Thunis and Cuvelier (2016), model performance criteria (MPC) were calculated for bias (BIAS), normalized mean bias (NMB), normalized mean standard deviation (NMSD), normalized root mean square error $\left(\mathrm{RMSE}_{\mathrm{U}}\right.$ ), and Pearson correlation coefficient $(r)$. MPC are based on the measurement uncertainties, which-for the previously listed stations-were calculated in the range of $9.6 \div 12.0 \mu \mathrm{g} / \mathrm{m}^{3}$ and $9.7 \div 16.6 \mu \mathrm{g} / \mathrm{m}^{3}$ for PM2.5 and PM10, respectively. Besides the statistics required by the Delta methodology, three other indicators were used to facilitate
Table 1 Results of the CALPUFF model: average, minimum, and maximum exposures to PM2.5, PM10, and PMc, in the seasons of the year (winter, December, January, and February (DJF); spring, March,
April, and May (MAM); summer, June, July, and August (JJA); autumn, September, October, and November (SON)) and in the whole 2013-2014 period

\begin{tabular}{|c|c|c|c|c|c|c|c|c|c|}
\hline & \multicolumn{3}{|c|}{$\operatorname{PM} 2.5\left(\mu \mathrm{g} / \mathrm{m}^{3}\right)$} & \multicolumn{3}{|c|}{$\operatorname{PM} 10\left(\mu \mathrm{g} / \mathrm{m}^{3}\right)$} & \multicolumn{3}{|c|}{ PMc $\left(\mu \mathrm{g} / \mathrm{m}^{3}\right)$} \\
\hline & Average & Min & Max & Average & Min & Max & Average & Min & Max \\
\hline DJF & 39.3 & 7.1 & 130.0 & 67.8 & 12.7 & 221.0 & 28.5 & 4.2 & 106.0 \\
\hline MAM & 24.1 & 6.0 & 75.7 & 46.1 & 12.8 & 145.5 & 22.1 & 4.3 & 69.8 \\
\hline JJA & 11.8 & 4.9 & 28.6 & 33.1 & 11.3 & 99.5 & 21.3 & 5.5 & 70.9 \\
\hline SON & 28.9 & 6.9 & 133.6 & 57.3 & 12.9 & 253.5 & 28.4 & 5.8 & 121.3 \\
\hline 2013-2014 & 25.7 & 4.9 & 133.6 & 50.7 & 11.3 & 253.5 & 24.9 & 4.2 & 121.3 \\
\hline
\end{tabular}


Fig. 1 Time series of populationweighted average daily PM2.5, PM10, and PMc concentrations $\left(\mu \mathrm{g} / \mathrm{m}^{3}\right)$ in Warsaw in 2013-2014, calculated by CALPUFF
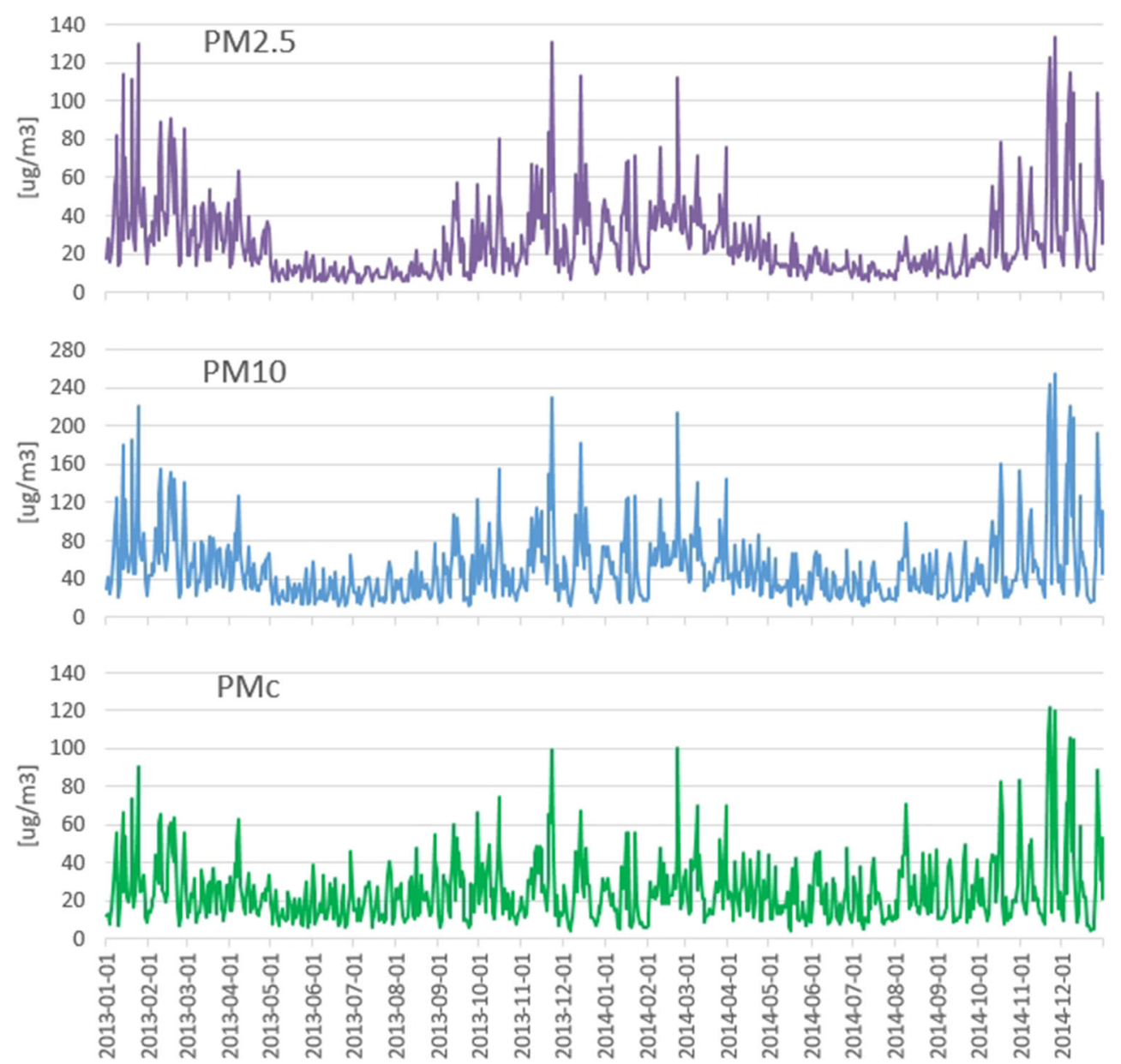

comparison with other models' performance evaluation: root mean square error-unnormalized (RMSE), skill variance (SKVAR, the ratio of modeled to measured standard deviations (SD)), and factor of two (FAC2). The formulation of these metrics can be found, e.g., in Juda-Rezler (2010) and Juda-Rezler et al. (2012). The results of the evaluation for the 24-h modeled concentrations after calibration are presented in Table 3.
In general, calibrated PM10 concentrations are underestimated in four cases and overestimated for two stations: Piastów and Tołstoja. MPCs were met for all 6 points in the case of BIAS, NMB, NMSD, and $r$, while MPC for $\mathrm{RMSE}_{\mathrm{U}}$ was kept only for the Targówek site. According to Thunis et al. (2012), $\mathrm{RMSE}_{\mathrm{U}}$ should stay below (or close to) 1 , and as shown in Table 3, the values do not exceed this threshold much, as they reach 1.1-1.2. Positive NMSD values

Table 2 Main characteristics of the PM measurement stations located within the Warsaw modeling domain

\begin{tabular}{|c|c|c|c|c|}
\hline Name & Type $^{\mathrm{a}}$ & $\begin{array}{l}\text { Automatic/ } \\
\text { manual }\end{array}$ & PM fraction & Remarks \\
\hline Anieli Krzywoń & UB & $\mathrm{M}$ & PM10 & \\
\hline Komunikacyjna & TRAF & $\mathrm{A}, \mathrm{M}$ & PM2.5, PM10 & \\
\hline Piastów & UB & $\mathrm{A}, \mathrm{M}$ & PM2.5, PM10 & $\begin{array}{l}\text { Station located in the outskirts of Warsaw, } \\
\text { around } 2 \mathrm{~km} \text { from the nearest receptor point in } \\
\text { modeling domain }\end{array}$ \\
\hline Targówek & UB & $\mathrm{A}, \mathrm{M}$ & PM2.5, PM10 & \\
\hline Tołstoja & UB & M & PM10 & \\
\hline Ursynów & UB & $\mathrm{A}, \mathrm{M}$ & PM2.5, PM10 & \\
\hline
\end{tabular}

${ }^{\mathrm{a}} U B$ urban background; TRAF traffic (kerbside) station 


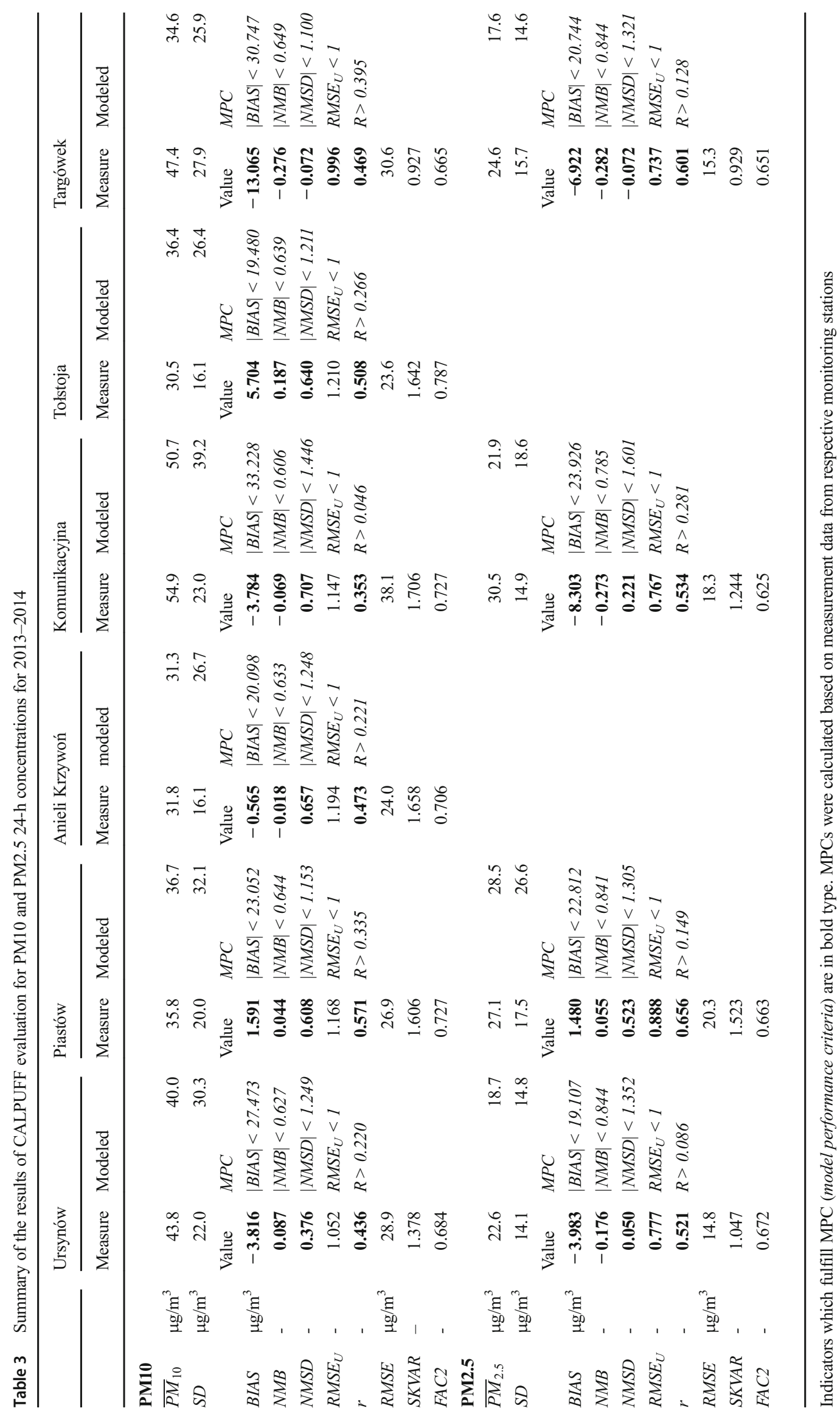


for those cases indicate that the elevated $\mathrm{RMSE}_{\mathrm{U}}$ is mainly due to amplified standard deviations of the model results (Carnevale et al. 2014), which in fact are a lot higher than $\mathrm{SD}$ of the measurements. It is worth mentioning that for PM even advanced chemical transport models (CTM) struggle and often fail to fulfill this criterion (Carnevale et al. 2014; Georgieva et al. 2015). Temporal correlation coefficient is in the range of $0.353 \div 0.571$, which is very much comparable with the results obtained for seven CTMs evaluated within the EURODELTA III project: $0.32 \div 0.62$ (Bessagnet et al. 2014). SKVAR records are well above unity $(1.378 \div 1.706)$ for five sites (besides Targówek, for which SKVAR = 0.927), which indicates that SD of modeled PM10 concentrations is indeed too high. This is due to the model own limitations, related to simplified turbulence parametrization, which fails to correctly represent concentrations in the case of stable atmospheric conditions, shallow mixing layer and low wind velocity. In such conditions, CALPUFF (similarly to other air quality models) tends to generate overestimated PM peaks, which are responsible for elevated variance and thus SD (Holnicki et al. 2016; Maciejewska 2017). The applied calibration procedure can handle these problems only to a limited extent. The percentage of model results which fall into the range of half to twice of the measured value (FAC2) reaches from 66.5 to $78.7 \%$, depending on the sampling point.

Calibrated PM2.5 concentrations are somewhat underestimated for three out of four measurement sites (excluding Ursynów). However, all MPCs for BIAS, NMB, $\mathrm{NMSD}, \mathrm{RMSE}_{\mathrm{U}}$, and $r$ were met in all four cases, indicating good model performance for fine PM prediction. Standard deviations were again higher for modeled values than for measured data, but SKVAR records were lower than in the case of PM10, and they ranged $0.929 \div 1.523$. Moreover, in this case, the elevated SD did not cause exceedance of MPC for the RMSE $_{U}$ statistics. Correlation coefficients reached $0.521 \div 0.656$, which is corresponding to the EURODELTA

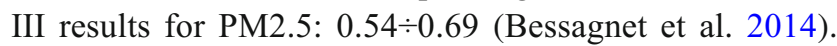
FAC2 records are similar for all four stations, and they range from 62.5 to $67.2 \%$.

In general, CALPUFF results for PM10 and PM2.5 after calibration are in good agreement with available measurement data in Warsaw domain, as shown with the application of both Delta methodology and conventional statistical indicators. PM2.5 predictions seem to be more precise than PM10, especially taking into consideration SD and all measures dependent on this statistic. Having it determined, the calibrated data

Table 4 The number of deaths and urgent hospital admissions due all causes, as well as cardiovascular (CV) and respiratory (RS) diseases in Warsaw in 2013-2014

Mortality

\begin{tabular}{|c|c|c|c|c|c|c|c|c|c|}
\hline \multirow[t]{2}{*}{2013} & \multicolumn{3}{|c|}{ ALL causes } & \multicolumn{3}{|c|}{ CV causes } & \multicolumn{3}{|c|}{ RS causes } \\
\hline & All & Female & Male & All & Female & Male & All & Female & Male \\
\hline Total & 17,747 & 9441 & 8306 & 8041 & 4492 & 3549 & 1789 & 892 & 897 \\
\hline in which $>65$ years & 12,403 & 7394 & 5009 & 6214 & 3969 & 2245 & 1411 & 760 & 651 \\
\hline Cold season & 9320 & 5005 & 4315 & 4179 & 2378 & 1801 & 1029 & 518 & 511 \\
\hline Warm season & 8427 & 4436 & 3991 & 3862 & 2114 & 1748 & 760 & 374 & 386 \\
\hline \multicolumn{10}{|l|}{2014} \\
\hline Total & 17,006 & 9001 & 8005 & 8004 & 4410 & 3594 & 1720 & 887 & 833 \\
\hline in which $>65$ years & 12,117 & 7108 & 5009 & 6185 & 3862 & 2323 & 1418 & 768 & 650 \\
\hline Cold season & 8829 & 4733 & 4096 & 4202 & 2339 & 1863 & 944 & 492 & 452 \\
\hline Warm season & 8177 & 4268 & 3909 & 3802 & 2071 & 1731 & 776 & 395 & 381 \\
\hline \multicolumn{10}{|l|}{ Hospitalizations } \\
\hline \multirow[t]{2}{*}{2013} & \multicolumn{3}{|c|}{ ALL causes } & \multicolumn{3}{|c|}{$\mathrm{CV}$ causes } & \multicolumn{3}{|c|}{ RS causes } \\
\hline & All & Female & Male & All & Female & Male & All & Female & Male \\
\hline Total & 16,615 & 9622 & 6993 & 2836 & 1316 & 1520 & 1301 & 579 & 722 \\
\hline in which $>65$ years & 4318 & 2387 & 1931 & 1361 & 769 & 592 & 223 & 84 & 139 \\
\hline Cold season & 7715 & 4476 & 3239 & 1336 & 625 & 711 & 649 & 301 & 348 \\
\hline Warm season & 8900 & 5146 & 3754 & 1500 & 691 & 809 & 652 & 278 & 374 \\
\hline \multicolumn{10}{|l|}{2014} \\
\hline Total & 17,805 & 10,256 & 7549 & 2856 & 1342 & 1514 & 1344 & 606 & 738 \\
\hline in which $>65$ years & 4612 & 2537 & 2075 & 1425 & 780 & 645 & 184 & 75 & 109 \\
\hline Cold season & 8915 & 5048 & 3867 & 1439 & 657 & 782 & 722 & 318 & 404 \\
\hline Warm season & 8890 & 5208 & 3682 & 1417 & 685 & 732 & 622 & 288 & 334 \\
\hline
\end{tabular}

Source: Data shared by National Institute of Public Health-National Institute of Hygiene 
obtained by CALPUFF simulation was further applied for short-term health effects assessment with the use of GAM models.

The data on the number of deaths and hospital admissions in Warsaw in 2013-2014 is summarized in Table 4.

Total number of deaths (excluding external causes) in Warsaw reached 17.7 and 17.0 thousand in 2013 and 2014, respectively. CV and RS-related mortality account for about $45 \%$ and $10 \%$ of all cases, respectively. Due to the fact that Warsaw population is dominated by women (54\% according to CSO 2016), the number of all-cause and CV female deaths is greater than for males; however, it is not the case for RS mortality, suggesting higher RS risks and mortality rates among men than women. Around $70 \%$ of all deaths concern people $>65$ years old, and both CV and RS disorders are the leading mortality causes among the elderly, who account for almost $80 \%$ of all deaths assigned to these groups. The allcause and CV mortality is about $10 \%$ higher during cold than warm season, while for RS causes, this effect is much more pronounced and results in 22-35\% increase of mortality during cold (heating) season.

In 2013 and 2014, the number of urgent hospitalizations reached 16.6 and 17.8 thousand, respectively, and was dominated by people younger than 65 years old (74\%). However, in the case of CV hospital admissions, almost half of the cases happened in the $>65$ age group. Seventeen percent of all hospitalizations were related to $\mathrm{CV}$ disorders, while respiratory causes accounted for $8 \%$ of cases. The distribution of hospitalizations between cold and warm seasons is ambiguous: in 2013, around $15 \%$ more cases happened during the warm season, while in 2014, the numbers were almost equal. One of the explanations could be related to quite hot summer of 2013 and thus elevated number of CV hospital admissions, as seen in Table 4.

Development of GAM models specific for Warsaw was initiated by fitting of penalized splines to represent self-determining, cyclic variability of mortality/morbidity in the population, as well as the influence of meteorological conditions. The procedure of choosing the best smoothing parameter was to minimize the sum of the first 30 terms of the PACF (partial autocorrelation) function and was done separately for each base GAM model. Figure 2 presents exemplary results of spline function shapes obtained for meteorological parameters. The basic shape of these dependencies was similar in all developed models; they differed mainly in the values of RR, especially between splines for mortality and for hospitalization (in the latter, the increase in risk was usually higher). Regarding temperature, its negative effect on health endpoints was the highest around $0{ }^{\circ} \mathrm{C}$ and above $25^{\circ} \mathrm{C}$. Higher wind speeds, lower air pressure, and extremely high and extremely low relative humidity are also related with increased health risk. In the case of precipitation, confidence interval is very wide, leading to the conclusion of insignificant influence of this parameter on the population health in Warsaw.
Fig. 2 Exemplary splines depicting the relationship between relative risk of mortality and meteorological parameters in Warsaw
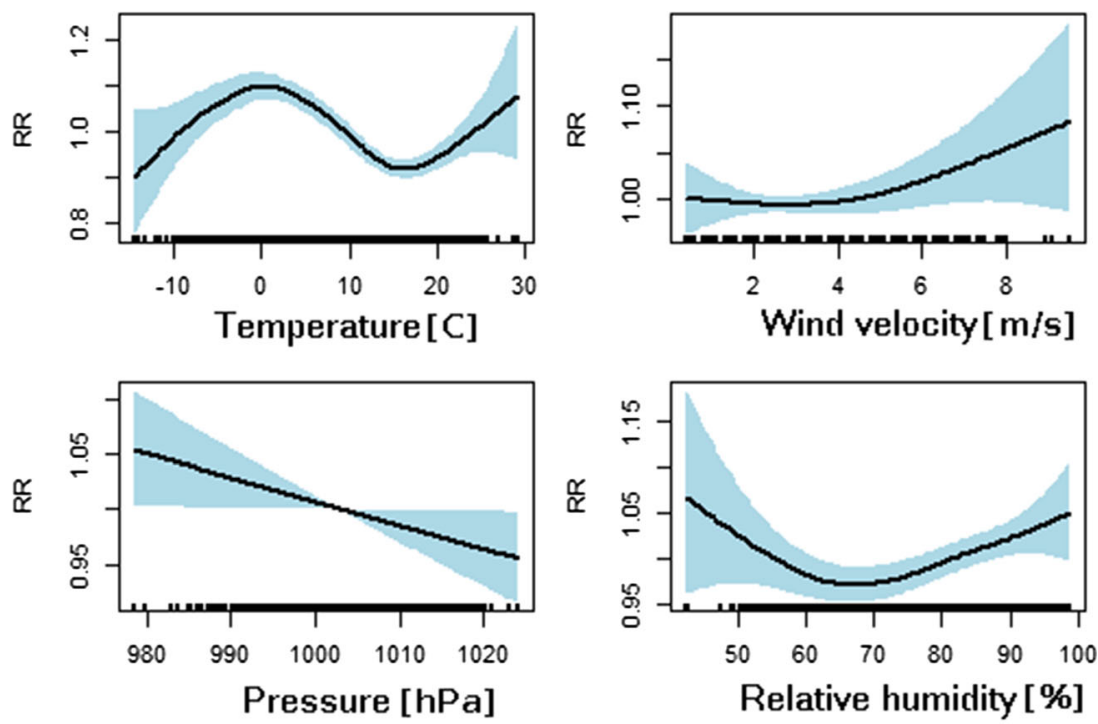

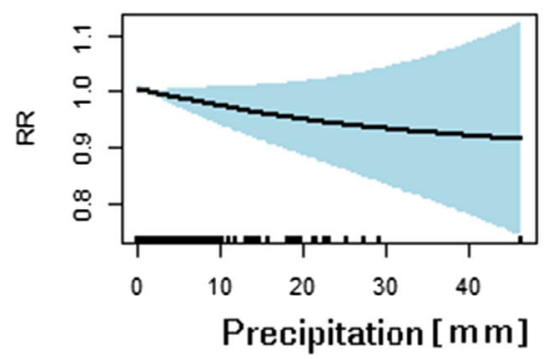


After fitting the base GAM models, they were complemented by the time series of PM concentrations. As the model is logarithmic, to obtain estimates of relative risk, the calculated factors had to be exponentially transformed. Table 5 presents the estimates of RR increase for ALL, CV, and RS mortality and hospitalizations in the whole population of Warsaw. The overall, statistically significant mortality risk increase for PM2.5 of $0.7 \%$ per $10 \mu \mathrm{g} / \mathrm{m}^{3}$ occurred on lag 0 , while for PM10 the risk increase of $0.3 \%$ per $10 \mu \mathrm{g} /$ $\mathrm{m}^{3}$ was delayed 2 days relatively to exposure (lag 2). PM2.5 and PM10 were also related to CV mortality: the risk increases reached $0.9 \%$ and $0.4 \%$ for PM2.5 (lag 0) and PM10 (lag 2), respectively. PMc influence on ALL, CV, and RS mortality risk in the whole population remained statistically insignificant in all three analyzed lags $(0,1$, and 2$)$.

In comparison with the results obtained by other authors, these estimates are comparable. In the research by Schwartz (2000), the increase of RR of mortality for PM10 in 10 US cities was calculated as $0.67 \%$, while in APHEA-2 project, the results varied from 0.27 to $0.45 \%$, depending on the city (Katsouyanni and Samet 2009). The results from the Mediterranean region (10 cities) estimate the short-term PM10 risk increase at the level of $0.32 \%$ (Samoli et al. 2013), while the values obtained in 4 Portuguese cities were higher and ranged $0.7-1.95 \%$ (Costa et al. 2014). The most recent study by Liu et al. (2019) reports pooled effects of $0.44 \%, 0.36 \%$, and $0.47 \%$ for all-cause, CV, and RS mortality, respectively, based on the results obtained for 652 cities worldwide (but none of them Polish). Present study falls well within this range, with somewhat lower estimate for allcause mortality $(0.3 \%)$ and very similar result for $\mathrm{CV}$ mortality $(0.4 \%)$.

In terms of PM2.5, the estimates are usually higher than for PM10, as shown also in the present research. Data obtained for Kraków by Jimenez et al. (2011) suggests the effect at the level of as much as $2.5 \%$, but most other results range from $0.55 \%$ in the Mediterranean region (Samoli et al. 2013), through $0.67 \%$ in Portugal (Garrett and Casimiro 2011), to $2.1 \%$ in Latin America (Atkinson et al. 2014). The results of Liu et al. (2019) for PM2.5 all-cause mortality risk increase $(0.68 \%)$ are almost the same as the value obtained for Warsaw $(0.7 \%)$; however, in terms of $\mathrm{CV}$ causes, Warsaw's estimate $(0.9 \%)$ exceeds the pooled effect $(0.55 \%)$ reported by Liu et al. (2019).

The short-term mortality influence of PMc is not studied as often as in the case of PM2.5 or PM10, and the results are less clear. The analysis of 12 studies done by Brunekreef and Forsberg (2005) revealed that only four of them proved the PMc influence on all-cause mortality, and two others report significant risk only in terms of CV deaths. Some results of more recent papers suggest the existence of statistically significant relation (e.g., Meister et al. 2012; Lee et al. 2015), while according to Samoli et al. (2013), there is no

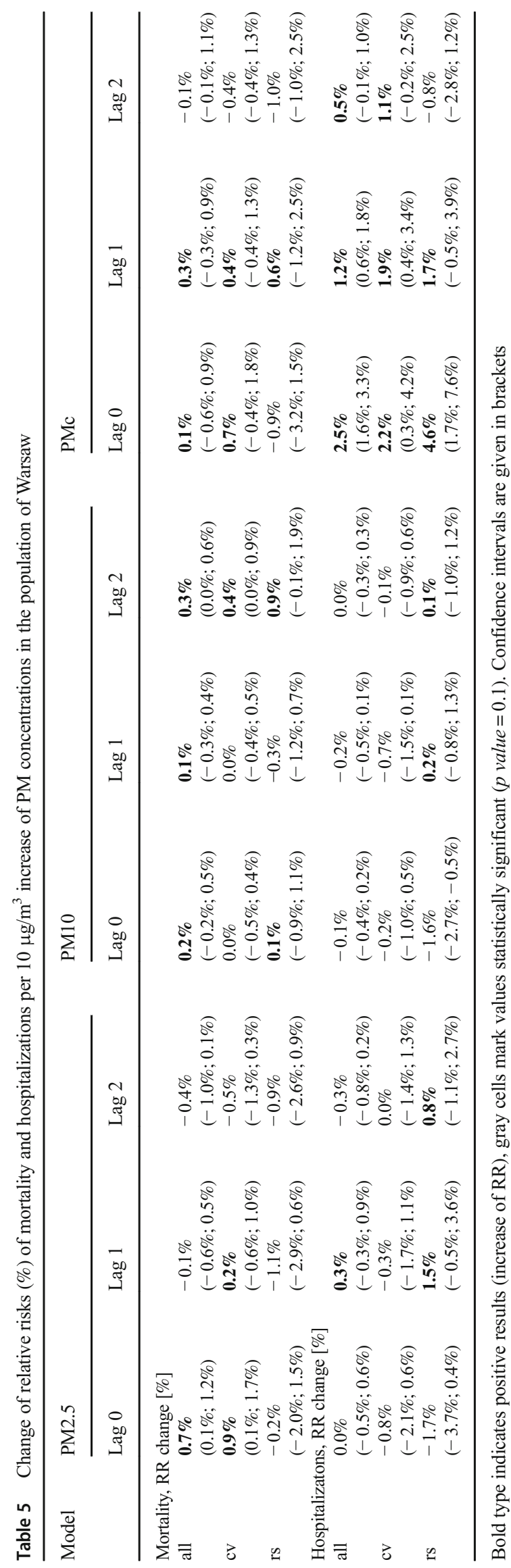


significant influence of PMc on either all-cause, $\mathrm{CV}$, or RS mortality in the investigated cities.

The results obtained in Warsaw show that in the case of PM2.5, its negative effect on mortality seems to be immediate, as the increases of risk occur mainly in the lag 0 analysis, and all statistically significant effects were also recorded for lag 0 . PM2.5 increases the risk of ALL and CV mortality, remaining not related to RS deaths. As seen in Fig. 3, the differences between gender or age groups are not significant in terms of PM2.5 effects on ALL, CV, or RS mortality, as the confidence intervals of relevant estimates overlap each other. PM10 effects on ALL and CV mortality turned out independent of age or gender, while in the case of RS, mortality significant effects are observed only in the sub-groups of elderly people (> 65 years, $1.4 \%)$ and males $(2.1 \%)$. The RR changes for PMc mortality related to ALL and CV causes were statistically significant only in the female group and in lag 0 reached $1.4 \%$ and $1.7 \%$, respectively. No significant influence of age was observed.

For comparison, RR calculations were also performed for the PM2.5 and PM10 daily means obtained from measurements at monitoring stations. The RR increase estimates for all-cause mortality were in this case a bit higher for both PM2.5 and PM10 and reached 1\% for PM2.5 in lag 1 and also $1 \%$ for PM10 in lag 0 (both statistically significant). Mortality risk was even higher when only CV causes were considered-RR increases in lag 0 reached $1.6 \%$ and $1.9 \%$ for PM2.5 and PM10, respectively, and for both fractions, the female sub-group turned out to be at higher risk (over 3\%). Similarly to model results, RS mortality revealed no significant association with neither PM2.5 nor PM10 measured concentrations; however, the (statistically insignificant) RR estimates were in general higher than in the case of modeled time series analysis.

Relative risk of hospitalizations in Warsaw is mainly related to PMc exposure, and the effect is rather immediatesignificant results were obtained for lag 0 and, to a lesser extent, for lag 1 analysis. The results for PM2.5 and PM10 are statistically insignificant. PMc overall hospitalization risk increase was calculated to be $2.5 \%$ per $10 \mu \mathrm{g} / \mathrm{m}^{3}$ in lag 0 , dropping to $1.2 \%$ in lag 1 . For all-cause morbidity, this PM fraction seems to affect both genders and age groups similarly,

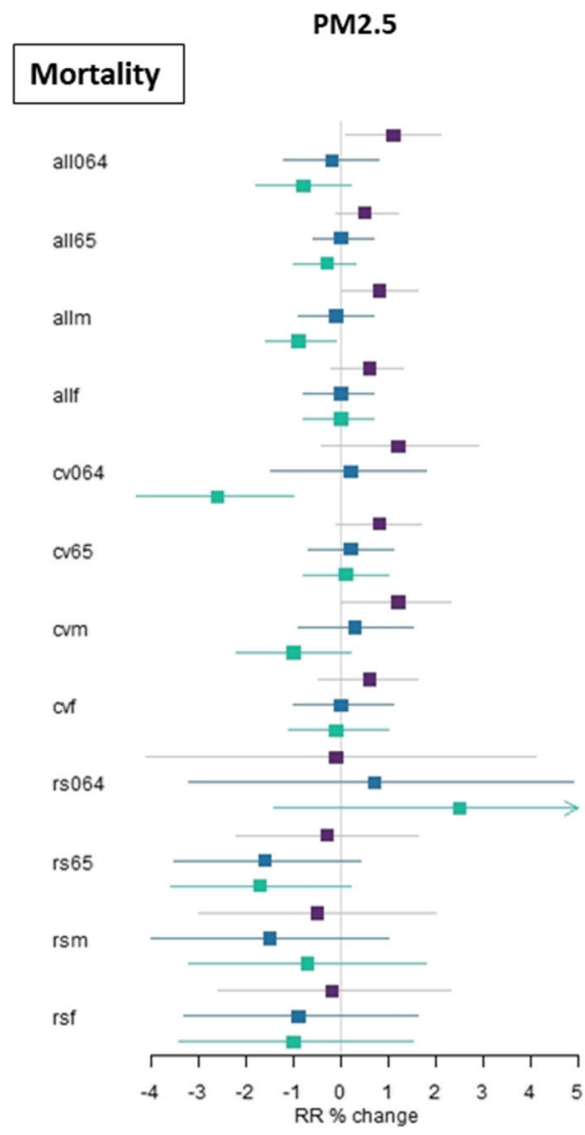

Fig. 3 Relative risk \% change of ALL, CV, and RS mortality (lags 0-2) in Warsaw's population sub-groups by age and gender, associated with exposition PM2.5, PM10, and PMc. Group names are constructed as follows: first, the type of causes (all-cause, all; cardiovascular, cv; respiratory, rs) is indicated; second, for each cause, two age groups are differentiated ( $0-64$ years old and above 65 years old); third, the grouping
PM10

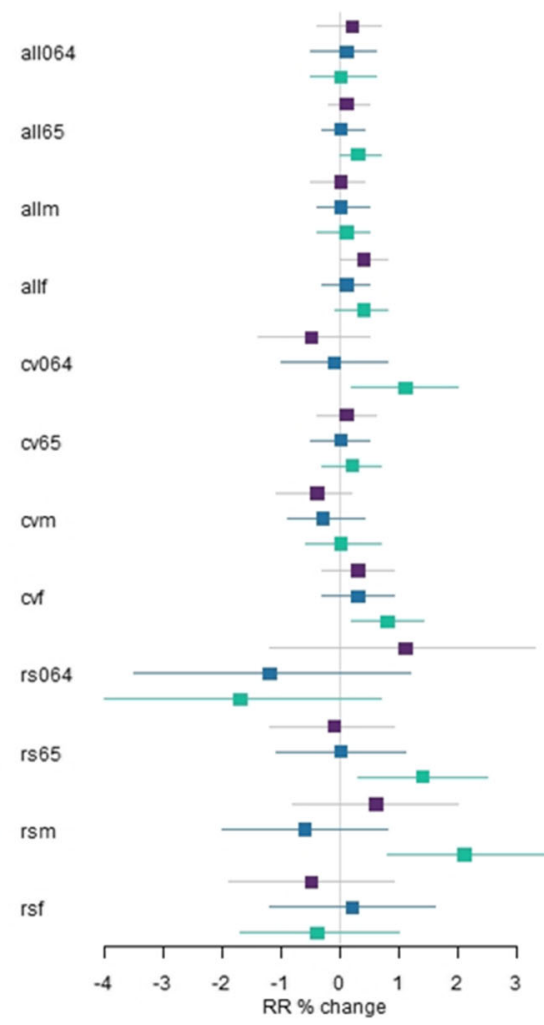

PMc

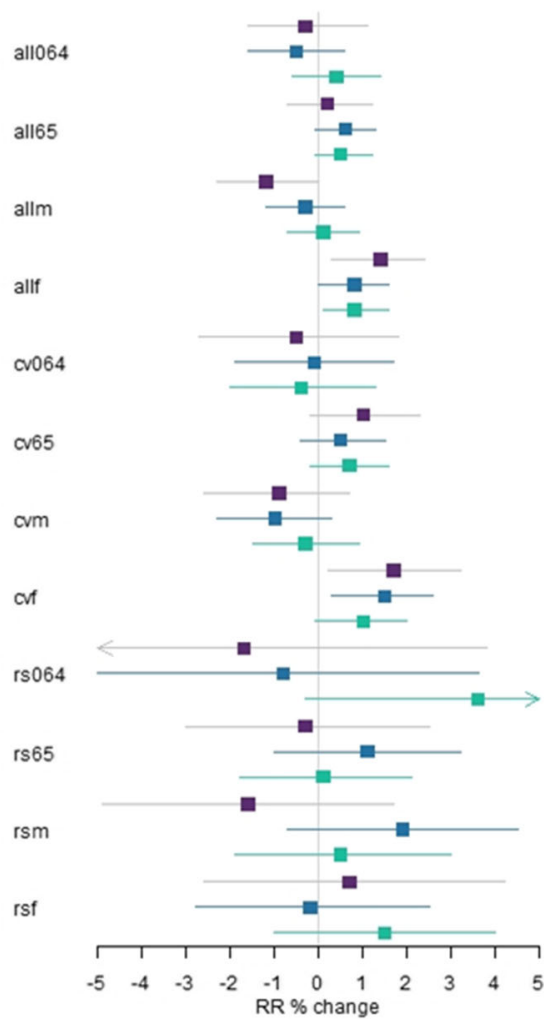

by gender (male, m; female, f) is presented. For example, "cv064" presents the results obtained for cardiovascular disease in the age group of 0 64 years, while "rsf" presents the results for respiratory causes within the female group. Confidence interval excluding 0 indicates statistical significance of the result 
presenting little or no differences in RR change estimates for selected sub-populations. Larger diversity is observed in terms of CV hospitalizations, for which the RR increases in the whole population were calculated as $2.2 \%$ and $1.9 \%$ in lag 0 and lag 1 , respectively. On lag 0 , the effect seems stronger for the elderly than for the 0-64 age group (4.7\% vs. 0\%) and for females than males ( $4.2 \%$ vs. $1.2 \%)$; however, in both cases, the confidence intervals are quite wide, and they partially overlap; therefore, these differences cannot be formally recognized as significant. Respiratory symptoms leading to hospitalization appear mostly immediately after exposure to PMc (lag 0 ), leading to the RR increase of $4.6 \%$ in the whole population. The highest estimates in RS morbidity were obtained for the age group of 0-64 years (5.2\%) and for males (5.3\%); however, as seen in Fig. 4, it is not possible to draw conclusions on the significant differences between age and gender groups, as the confidence intervals of the estimates are too wide.

Scarce results from other studies do not lead to clear conclusions regarding PMc-related risk of morbidity. Brunekreef and Forsberg (2005) showed that PMc RR increases for both
CV and RS hospitalizations (2-10\% per $10 \mu \mathrm{g} / \mathrm{m}^{3}$ ) are often higher than the values for PM2.5, while the estimates reported by Stafoggia et al. (2013) for southern Europe are much lower-below $0.5 \%$ for both $\mathrm{CV}$ and RS. In other works, PMc was either only related to RS but not CV morbidity (e.g., Halonen et al. 2009; Atkinson et al. 2010) or conversely to CV but not RS (e.g. Peng et al. 2009). On the contrary to the present work, some studies prove that PM2.5 and PM10 also increase the relative risk of hospitalizations. In their metaanalysis, Atkinson et al. (2014) showed significant influence of PM2.5 on CV morbidity (0.9\%), but not on RS hospitalizations (excluding the western Pacific region, where this effect is significant and strong, 2.4\%). Sarnat et al. (2008) and Stafoggia et al. (2013) also reported an increase in morbidity RR due to PM2.5 exposure. PM10 was found to increase the risk of all-cause (Costa et al. 2014), CV (Katsouyanni and Samet 2009; Stafoggia et al. 2013; Pun et al. 2014), as well as RS (Andersen et al. 2007; Katsouyanni and Samet 2009; Stafoggia et al. 2013) hospitalizations. In most cases, the RR values for RS hospital admissions are higher than for the $\mathrm{CV}$ cases.

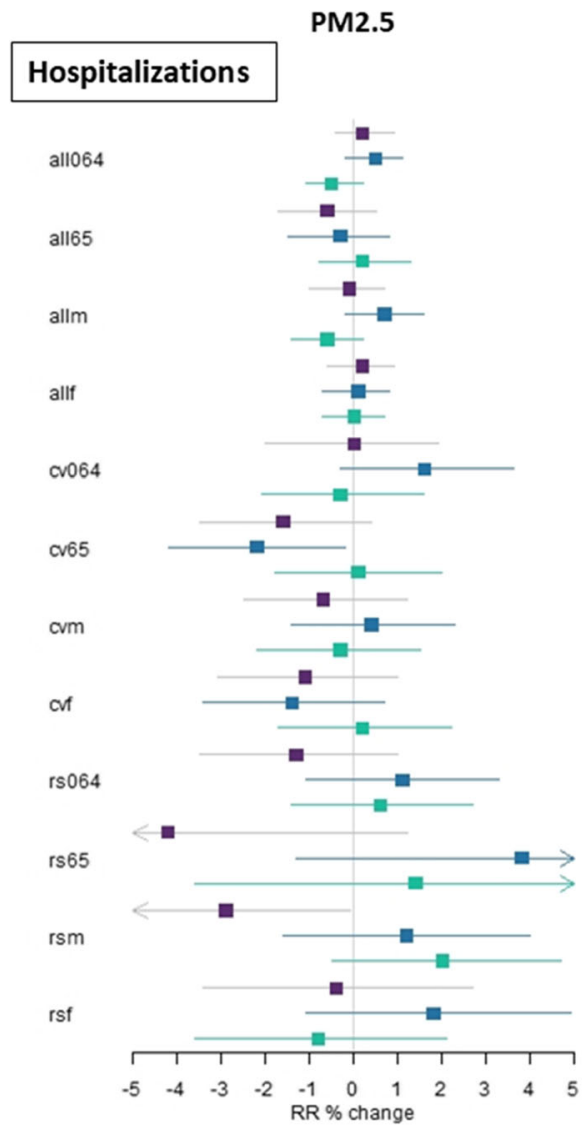

Fig. 4 Relative risk \% change of ALL, CV and RS hospitalization (lags $0-2$ ) in Warsaw's population sub-groups by age and gender, associated with exposition PM2.5, PM10, and PMc. Group names are constructed as follows: first, the type of causes (all-cause, all; cardiovascular, cv; respiratory, rs) is indicated; second, for each cause two age groups are differentiated ( $0-64$ years old and above 65 years old); third, the grouping
PM10 $\operatorname{lag} 0 \square \operatorname{lag} 1 \square \operatorname{lag} 2$

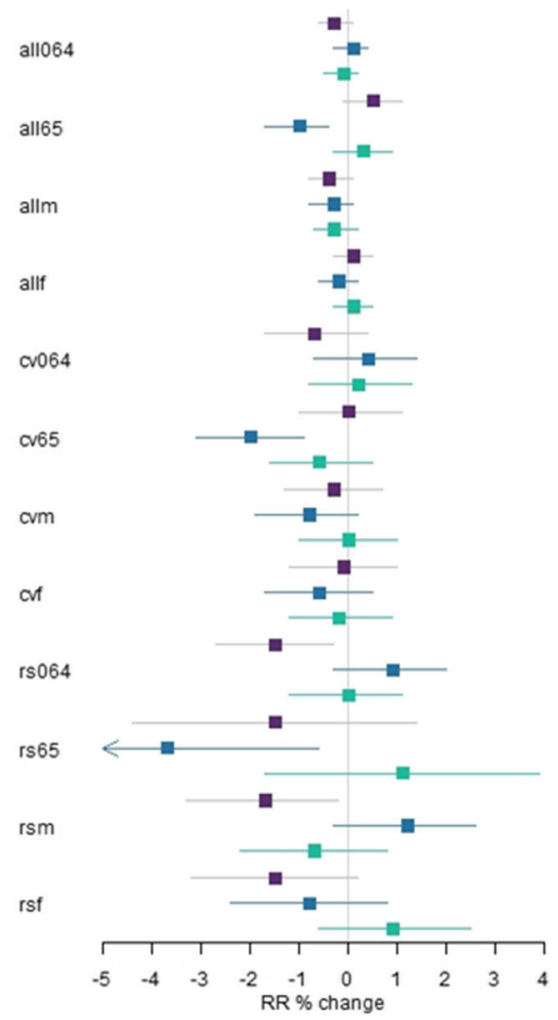

by gender (male, m; female, f) is presented. For example, "cv064" presents the results obtained for cardiovascular disease in the age group of 0 64 years, while "rsf" presents the results for respiratory causes within the female group. Confidence interval excluding 0 indicates statistical significance of the result 
Obtained RR increase estimates for hospital admissions were also compared with the values resulting from time series analysis based on monitoring data. In the latter case, the allcause hospitalization risk increase was $2.5 \%$ (lag 0 ) for PM2.5 and $1.5 \%$ (lag 0 ) for PM10-both values statistically significant. CV hospital admissions were associated only with PM2.5 levels (risk increase of $2.3 \%$ in lag 1), with higher risks observed among the 0-64 years age group (4\% in lag 2) and among males (3.5\% in lag 1$)$. Also RS hospitalizations showed significant relationship only with PM2.5 concentrations $(7.7 \%$ in lag 0$)$, with increased risk for females $(9.6 \%$ in lag 0 ) and in the $0-64$ years age group ( $8.1 \%$ in lag 0$)$. Neither CV nor RS levels were significantly associated with PM10; however, in both cases, the RR increases were positive. The differences between the risk change estimates obtained for modeled and measured PM levels result primarily from the fact that the modeled concentrations were averaged over the whole domain covering the city, while measurements of PM are conducted only in a few individual points. The inaccuracy of model results is another possible cause of these discrepancies.

The insignificant estimates of PM2.5 and PM10 relative risk of morbidity obtained in the present work might in fact result from too short period of analysis or other unrevealed factors, as the RR changes are in general positive; however, their confidence intervals are too wide to admit their statistical significance. Contrarily, different results obtained in various localizations might be an effect of inconstant PM composition (and thus toxicity), dependent on peculiar structures of emission sources that affect particular cities/regions.

\section{Conclusion}

The investigation on short-term health effects of particulate matter in the biggest Polish city has proven that, alike in other urban centers throughout the world, the population of Warsaw suffers an elevated mortality and morbidity risk due to the short time exposure to air pollution. The results show that premature deaths are mainly related to immediate (lag 0) PM2.5 and delayed (lag 2) PM10 exposures, while the risk of hospitalizations increases with elevated PMc levels. Cardiovascular diseases are associated with both fine and coarse PM fractions, while the respiratory ones seem to be related rather to PMc. The advantage of the presented study is that it involved statistical data on mortality and hospital admissions, which is relatively easily accessible and, more importantly, comprehensible for researchers unproficient in medicine. However, the two main limitations of the presented results are the short time series (2-year dataset) and the analyses limited to only one city. The applied epidemiological approach itself has also its restrictions. Statistical data analysis aims at differentiating hypothetical signal (i.e., some existing relationship between the investigated environmental factor(s) and the endpoint(s)) from the noise. Too small datasets, missing observations, errors in the data, and the influence of some omitted/neglected factors might impede or even preclude drawing reliable conclusions or at least substantially increase the level of uncertainty of the results. Nonetheless, there is a wide reference material concerning the results of epidemiological studies across the world, which allows for meta-analyses, such as those implemented by Katsouyanni et al. (2001) or Liu et al. (2019). Hence, it is necessary to perform such studies especially in the regions not analyzed before, in order to complement the knowledge on the possible ranges of adverse health effects of air pollution, and to improve the preventive measures of negative social impacts. In the case of PM, an important direction of further research should be to investigate which components, types, and sources of particles pose the highest risk in terms of human health and which specific health outcomes could be assigned to respective types or mixtures of PM, as for such a complex pollutant the effective prevention is possible only after an extensive recognition of this problem.

Acknowledgments The author would like to thank the National Institute of Public Health-National Institute of Hygiene for sharing the epidemiological data, Dr. Daniel Rabczenko for methodological help, and Prof. Katarzyna Juda-Rezler for valuable comments and critical analysis of the study.

Funding information This work was supported by the Polish National Science Centre under OPUS funding scheme 7th edition, Project no. UMO-2014/13/B/ST10/01096.

Open Access This article is licensed under a Creative Commons Attribution 4.0 International License, which permits use, sharing, adaptation, distribution and reproduction in any medium or format, as long as you give appropriate credit to the original author(s) and the source, provide a link to the Creative Commons licence, and indicate if changes were made. The images or other third party material in this article are included in the article's Creative Commons licence, unless indicated otherwise in a credit line to the material. If material is not included in the article's Creative Commons licence and your intended use is not permitted by statutory regulation or exceeds the permitted use, you will need to obtain permission directly from the copyright holder. To view a copy of this licence, visit http://creativecommons.org/licenses/by/4.0/.

\section{References}

Andersen ZJ, Wahlin P, Raaschou-Nielsen O, Scheike T, Loft S (2007) Ambient particle source apportionment and daily hospital admissions among children and elderly in Copenhagen. J Exp Sci Environ Epidemiol 17:625-636. https://doi.org/10.1038/sj.jes. 7500546

Atkinson RW, Fuller GW, Anderson HR, Harrison RM, Armstrong B (2010) Urban ambient particle metrics and health: a time-series analysis. Epidemiology 21:501-511. https://doi.org/10.1097/EDE. 0b013e3181 debc 88 
Atkinson RW, Kang S, Anderson HR, Mills IC, Walton HA (2014) Epidemiological time series studies of PM2.5 and daily mortality and hospital admissions: a systematic review and meta-analysis. Thorax 69:660-665. https://doi.org/10.1136/thoraxjnl-2013-204492

Badyda AJ, Gayer A, Czechowski PO, Majewski G, Dąbrowiecki P (2016) Pulmonary function and incidence of selected respiratory diseases depending on the exposure to ambient PM10. Int J Mol Sci 17:1954. https://doi.org/10.3390/ijms17111954

Barclay J \& Scire J (2011). Generic guidance and optimum model settings for the CALPUFF modeling system for inclusion into the approved methods for the modeling and assessments of air pollutants in NSW, Australia, Atmospheric Studies Group, TRC Environmental Corporation, Lowell 2011

Belis CA, Karagulian F, Larsen BR, Hopke PK (2013) Critical review and meta-analysis of ambient particulate matter source apportionment using receptor models in Europe. Atmos Environ 69:94-108. https://doi.org/10.1016/j.atmosenv.2012.11.009

Bell ML, Davis DL (2001) Reassessment of the lethal London fog of 1952: novel indicators of acute and chronic consequences of acute exposure to air pollution. Environ Health Perspect 109(Suppl. 3): 389-394. https://doi.org/10.1289/ehp.01109s3389

Bessagnet, B., Colette, A., Meleux, F., Rouil, L. et al. (2014). The EURODELTA III exercise - model evaluation with observations issued from the 2009 EMEP intensive period and standard measurements in Feb/Mar 2009. TFMM \& MSC-W Technical Report 1 /2014 (http://emep.int/publ/reports/2014/MSCW_technical_1_ 2014.pdf (07.09.2018))

Brunekreef B, Forsberg B (2005) Epidemiological evidence of effects of coarse airborne particles on health. Eur Respir J 26:309-318. https:// doi.org/10.1183/09031936.05.00001805

Carnevale C, Finzi G, Pederzoli A, Pisoni E, Thunis P, Turrini E, Volta M (2014) Applying the delta tool to support the air quality directive: evaluation of the TCAM chemical transport model. Air Qual Atmos Health 7:335-346. https://doi.org/10.1007/s11869-014-0240-4

Cassee FR, Heroux M-E, Gerlofs-Nijland ME, Kelly FJ (2013) Particulate matter beyond mass: recent health evidence on the role of fractions, chemical constituents and sources of emission. Inhal Toxicol 25:802-812. https://doi.org/10.3109/08958378.2013. 850127

Costa S, Ferreira J, Silveira C, Costa C, Lopes D, Relvas H, Borrego C, Roebeling P, Miranda AI, Teixeira JP (2014) Integrating health on air quality assessment - review report on health risks of two major European outdoor air pollutants: PM and NO2. J Toxicol Environ Health Part B: Crit Rev 17:307-340. https://doi.org/10.1080/ 10937404.2014.946164

CSO (2016) Area and population in the territorial profile in 2016. Central Statistical Office, Warsaw

Dominici F, McDermott A, Zeger SL, Samet JM (2002) On the use of generalized additive models in time-series studies of air pollution and health. Am J Epidemiol 156:193-203. https://doi.org/10.1093/ aje/kwf062

EEA (2017). Air quality in Europe - 2017 report. Report no. 13/2017 (https://www.eea.europa.eu/publications/air-quality-in-europe-2017 (09.09.2017))

Forouzanfar MH, Alexander L, Anderson HR, Bachman VF et al (2015) Global, regional, and national comparative risk assessment of 79 behavioural, environmental and occupational, and metabolic risks or clusters of risks in 188 countries, 1990-2013: a systematic analysis for the Global Burden of Disease Study 2013. Lancet 386: 2287-2323. https://doi.org/10.1016/S0140-6736(15)00128-2

Garrett P, Casimiro E (2011) Short-term effect of fine particulate matter (PM2.5) and ozone on daily mortality in Lisbon, Portugal. Environ Sci Pollut Res 18:1585-1592. https://doi.org/10.1007/s11356-0110519-z

Georgieva E, Syrakov D, Prodanova M, Etropolska I, Slavov K (2015) Evaluating the performance of WRF-CMAQ air quality modelling system in Bulgaria by means of the DELTA tool. Int J Environ Pollut 57:272-284. https://doi.org/10.1504/IJEP.2015.074512

Halonen JI, Lanki T, Yli-Tuomi T, Tiittanen P, Kulmala M, Pekkanen J (2009) Particulate air pollution and acute cardiorespiratory hospital admissions and mortality among the elderly. Epidemiology 20:143153. https://doi.org/10.1097/EDE.0b013e31818c7237

Holmes NS, Morawska L (2006) A review of dispersion modelling and its application to the dispersion of particles: an overview of different dispersion models available. Atmos Environ 40:5902-5928. https:// doi.org/10.1016/j.atmosenv.2006.06.003

Holnicki P, Kałuszko A, Trapp W (2016) An urban scale application and validation of the CALPUFF model. Atmo Poll Res 7:393-402. https://doi.org/10.1016/j.apr.2015.10.016

Holnicki P, Tainio M, Kałuszko A, Nahorski Z (2017a) Burden of mortality and disease attributable to multiple air pollutants in Warsaw Poland. Int J Environ RePublic Health 14:1359. https://doi.org/10. 3390/ijerph14111359

Holnicki P, Kałuszko A, Nahorski Z, Stankiewicz K, Trapp W (2017b) Air quality modeling for Warsaw agglomeration. Arch Environ Protect 43:48-64. https://doi.org/10.1515/aep-2017-0005

Holnicki P, Kałuszko A, Nahorski Z, Tainio M (2018) Intra-urban variability of the intake fraction from multiple emission sources. Atmos Poll Res 9:1184-1193. https://doi.org/10.1016/j.apr.2018.05.003

IARC (2013). Outdoor air pollution a leading environmental cause of cancer deaths. Press Release $N^{\circ} 221,17$ October 2013, Lyon/ Geneva (https://www.iarc.fr/en/media-centre/iarcnews/pdf/pr221 E.pdf (17.08.2018))

Jimenez E, Linares C, Martinez D, Diaz J (2011) Particulate air pollution and short-term mortality due to specific causes among the elderly in Madrid (Spain): seasonal differences. Int J Environ Health Res 21: 372-390. https://doi.org/10.1080/09603123.2011.560251

Juda-Rezler K (2010) New challenges in air quality and climate modelling. Arch Environ Protect 36(1):3-28

Juda-Rezler, K. \& Toczko, B. (2016). Fine particulate matter in the atmosphere. Compendium of knowledge about air pollution by suspended particles in Poland, Biblioteka Monitoringu Srodowiska, Warsaw 2016

Juda-Rezler K, Reizer M, Oudinet JP (2011) Determination and analysis of PM10 source apportionment during episodes of air pollution in Central Eastern European urban areas: the case of wintertime 2006. Atmos Environ 45:6557-6566. https://doi.org/10.1016/j.atmosenv. 2011.08.020

Juda-Rezler K, Reizer M, Huszar P, Krüger BC, Zanis P, Syrakov D, Katragkou E, Trapp W, Melas D, Chervenkov H, Tegoulias I, Halenka T (2012) Modelling the effects of climate change on air quality over Central and Eastern Europe: concept, evaluation and projections. Clim Res 53:179-203. https://doi.org/10.3354/cr01072

Juda-Rezler K, Reizer M, Maciejewska K, Błaszczak B, Klejnowski K (2020) Characterization of atmospheric PM2.5 sources at a Central European urban background site. Sci Total Environ 713:136729. https://doi.org/10.1016/j.scitotenv.2020.136729

Katsouyanni K, Samet JM (2009) Air pollution and health: a European and North American approach (APHENA). Health Effects Institute, Boston

Katsouyanni K, Touloumi G, Samoli E, Gryparis A, Le Tertre A, Monopolis Y, Rossi G, Zmirou D, Ballester F, Boumghar A, Anderson HR, Wojtyniak B, Paldy A, Braunstein R, Pekkanen J, Schindler C, Schwartz J (2001) Confounding and effect modification in the short-term effects of ambient particles on total mortality: results from 29 European cities within the APHEA2 project. Epidemiology 12:521-531. https://doi.org/10.1097/00001648200109000-00011

Kim K-H, Kabir E, Kabir S (2015) A review on the human health impact of airborne particulate matter. Environ Int 74:136-143. https://doi. org/10.1016/j.envint.2014.10.005 
Lee CJ, Martin RV, Henze DK, Brauer M, Cohen A, van Donkelaar A (2015) Response of global particulate-matter related mortality to changes in local precursor emissions. Environ Sci Technol 49: 4335-4344. https://doi.org/10.1021/acs.est.5b00873

Liu C, Chen R, Sera F, Vicedo-Cabrera AM, Guo Y, Tong S, Coelho MSZS, Saldiva PHN, Lavigne E, Matus P, Valdes ON, Osorio GS, Pascal M, Stafoggia M, Scortichini M, Hashizume M, Honda Y, Hurtado-Díaz M, Cruz J, Nunes B, Teixeira JP, Kim H, Tobias A, Íñiguez C, Forsberg B, Åström C, Ragettli MS, Guo Y-L, Chen B-Y, Bell ML, Wright CY, Scovronick N, Garland RM, Milojevic A, Kyselý J, Urban A, Orru H, Indermitte E, Jaakkola JJK, Ryti NRI, Katsouyanni K, Analitis A, Zanobetti A, Schwartz J, Chen J, Wu T, Cohen A, Gasparrini A, Kan H (2019) Ambient particulate air pollution and daily mortality in 652 cities. N Engl J Med 381:705-715. https://doi.org/10.1056/NEJMoa1817364

Maciejewska K. (2017). Analysis of the short-term impact of various types of particulate matter on health of the inhabitants of Warsaw. Doctoral dissertation, Warsaw University of Technology

Maciejewska K, Juda-Rezler K, Reizer M, Klejnowski K (2015) Modelling of black carbon statistical distribution and return periods of extreme concentrations. Environ Model Softw 74:212-226. https://doi.org/10.1016/j.envsoft.2015.04.016

Meister K, Johansson C, Forsberg B (2012) Estimated short-term effects of coarse particles on daily mortality in Stockholm, Sweden. Environ Health Perspect 120:431-436. https://doi.org/10.1289/ ehp. 1103995

Peng RD, Bell ML, Geyh AS, McDermott A, Zeger SL, Samet JM, Dominici F (2009) Emergency admissions for cardiovascular and respiratory diseases and the chemical composition of fine particle air pollution. Environ Health Perspect 117:957-963. https://doi.org/10. 1289/ehp.0800185

Pun VC, Yu ITS, Qiu H, Ho KF, Sun Z, Louie PKK, Wong TW, Tian L (2014) Short-term associations of cause-specific emergency hospitalizations and particulate matter chemical components in Hong Kong. Am J Epidemiol 179:1086-1095. https://doi.org/10.1093/ aje/kwu026

Rabczenko D, Wojtyniak B (2005) Methods of time-series analysis in assessment of the impact of ambient air pollution on mortality. Przegl Epidemiol 59:961-968 (in Polish)

Rabczenko D, Wojtyniak B, Wysocki M, Goryński P (2005) Short-term impact of air pollution by sulfur dioxide, particulate matter and nitrogen dioxide on mortality in Polish cities. Przegl Epidemiol 59:969-979 (in Polish)

Reizer M, Juda-Rezler K (2016) Explaining the high PM10 concentrations observed in Polish urban areas. Air Qual Atmos Health 9:517531. https://doi.org/10.1007/s11869-015-0358-z

Royal College of Physicians (2016). Every breath we take: the lifelong impact of air pollution. Report of a working party, RCP, London 2016

Rückerl R, Schneider A, Breitner S, Cyrys J, Peters A (2011) Health effects of particulate air pollution: a review of epidemiological evidence. Inhal Toxicol 23:555-592. https://doi.org/10.3109/ 08958378.2011 .593587
Samoli E, Stafoggia M, Rodopoulou S, Ostro B, Declercq C, Alessandrini E, Díaz J, Karanasiou A, Kelessis AG, Le Tertre A, Pandolfi P, Randi G, Scarinzi C, Zauli-Sajani S, Katsouyanni K, Forastiere F, MED-PARTICLES Study Group (2013) Associations between fine and coarse particles and mortality in Mediterranean cities: results from the MED-PARTICLES project. Environ Health Perspect 121:932-938. https://doi.org/10.1289/ehp

Sarnat JA, Marmur A, Klein M, Kim E, Russel AG, Sarnat SE, Moulholland JA, Hopke PK, Tolbert PE (2008) Fine particle sources and cardiorespiratory morbidity: an application of chemical mass balance and factor analytical source-apportionment methods. Environ Health Perspect 116:459-466. https://doi.org/10.1289/ehp. 10873

Schwartz J (2000) The distributed lag between air pollution and daily deaths. Epidemiology 11:320-326. https://doi.org/10.1097/ 00001648-200005000-00016

Sówka I, Zwoździak A, Trzepla-Nabaglo K, Skrętowicz M, Zwoździak J (2012) PM2.5 elemental composition and source apportionment in a residential area of Wrocław, Poland. Environ Prot Eng 38:73-79

Stafoggia M, Samoli E, Alessandrini E, Cadum E, Ostro B, Berti G, Faustini A, Jacquemin B, Linares C, Pascal M, Randi G, Ranzi A, Stivanello E, Forastiere F, MED-PARTICLES Study Group (2013) Short-term associations between fine and coarse particulate matter and hospitalizations in Southern Europe: results from the MEDPARTICLES project. Environ Health Perspect 121:1026-1033. https://doi.org/10.1289/ehp

Tainio M (2015) Burden of disease caused by local transport in Warsaw, Poland. J Transport Health 2:423-433. https://doi.org/10.1016/j.jth. 2015.06.005

Tainio M, Holnicki P, Loh MM, Nahorski Z (2014) Intake fraction variability between air pollution emission sources inside an urban area. Risk Anal 34:2021-2034. https://doi.org/10.1111/risa.12221

Thunis, P. \& Cuvelier, C. (2016). DELTA Version 5.4. Concepts/User's Guide/Diagrams, (http://fairmode.jrc.ec.europa.eu/document/ fairmode/WG1/DELTA_UserGuide_V5_4.pdf (10.08.2018))

Thunis P, Pederzoli A, Pernigotti D (2012) Performance criteria to evaluate air quality modeling applications. Atmos Environ 59:476-482. https://doi.org/10.1016/j.atmosenv.2012.05.043

WHO (2013) Review of evidence on health aspects of air pollution REVIHAAP project technical report. World Health Organization, Regional Office for Europe, European Centre for Environment and Health, Bonn

WHO (2014). 7 million premature deaths annually linked to air pollution. News Release, 25 March 2014, (http://www.who.int/mediacentre/ news/releases/2014/air-pollution/en/ (26.08.2018))

Wojtyniak B, Piekarski T (1996) Short term effect of air pollution on mortality in Polish urban populations - what is different? J Epidemiol Community Health 50(Suppl 1):S36-S41. https://doi. org/10.1136/jech.50.suppl_1.s36

Publisher's note Springer Nature remains neutral with regard to jurisdictional claims in published maps and institutional affiliations. 